\title{
Effectiveness of school-home intervention for adolescent obesity prevention: parallel school randomised study
}

\author{
Michele R. Sgambato ${ }^{1 *}$, Diana B. Cunha ${ }^{1}$, Bárbara S. N. Souza ${ }^{2}$, Viviana T. Henriques ${ }^{1}$, \\ Renata R. M. Rodrigues ${ }^{1}$, Ana L. V. Rêgo ${ }^{3}$, Rosangela A. Pereira ${ }^{3}$, Edna M. Yokoo ${ }^{2}$ and Rosely Sichieri ${ }^{1}$ \\ ${ }^{1}$ Department of Epidemiology, Institute of Social Medicine, State University of Rio de Janeiro, Rio de Janeiro 20550-900, Brazil \\ ${ }^{2}$ Department of Epidemiology, Fluminense Federal University, Rio de Janeiro 24030-210, Brazil \\ ${ }^{3}$ Department of Social and Applied Nutrition, Federal University of Rio de Janeiro, Rio de Janeiro 21941-590, Brazil
}

(Submitted 4 April 2019 - Final revision received 3 July 2019 - Accepted 18 July 2019)

\section{Abstract}

Many school-based interventions for obesity prevention have been proposed with positive changes in behaviour, but with unsatisfactory results on weight change. The objective was to verify the effectiveness of a combined school- and home-based obesity prevention programme on excessive weight gain in adolescents. Teachers delivered the school-based primary prevention programme to fifth- and sixth-graders (nine schools, forty-eight control classes, forty-nine intervention classes), which included encouraging healthy eating habits and physical activity. A subgroup of overweight or obese adolescents also received a home-based secondary prevention programme delivered by community health professionals. Schools were randomised to intervention or control group. Intent-to-treat analysis used mixed models for repeated continuous measures and considered the cluster effect. The main outcomes were changes in BMI and percentage body fat (\%body fat) after one school-year of intervention and follow-up. Against our hypothesis, BMI increased more in the intervention group than in the control group $\left(\Delta=0.3 \mathrm{~kg} / \mathrm{m}^{2} ; P=0.05\right)$ with a greater decrease in \%body fat among boys $(\Delta=-0.6 \% ; P=0.03)$ in the control group. The intervention group increased physical activity by $12.5 \mathrm{~min}$ per week compared with the control group. Female adolescents in the intervention group ate healthier items more frequently than in the control group. The subgroup that received both the school and home interventions had an increase in \%body fat than in the control group $(\Delta=0.89 \% ; P=0.01)$. In the present study, a behavioural change led to a small increase in physical activity and healthy eating habits but also to an overall increase in food intake.

Key words: Obesity prevention: Intervention: Adolescents

The worldwide prevalence of obesity has risen dramatically among children and adolescents, increasing from $4 \%$ in 1975 to over $18 \%$ in 2016 among those aged $5-19$ years ${ }^{(1)}$. Brazil is a part of this scenario with approximately $22 \%$ of adolescents classified as being overweight or obese in the 2013-2014 National School Survey $^{(2)}$. In line with this, Brazilian adolescents' diet is characterised by a low intake of fruits and vegetables and a high intake of sugar-sweetened beverages and sweets ${ }^{(3)}$.

Obesity prevention programmes for children and adolescents are considered an important strategy to reduce obesity ${ }^{(4)}$; commonly, schools are the central focus of interventions. Interactive classroom activities, including culinary classes, group discussion and educational games about healthy eating habits, have been extensively used in an attempt to improve eating behaviour; however, evidence of school-based strategies to reduce the prevalence of obesity is minimal ${ }^{(5)}$.
A detailed review of school-based interventions for obesity prevention suggests that more comprehensive interventions, with longer follow-ups and with parental participation, were only mildly effective in reducing $\mathrm{BMI}^{(6)}$. The lack of school-home partnership was considered the major explanation for the many unsuccessful school-based interventions ${ }^{(7)}$. In addition, a meta-analysis reported that the exclusion of unbalanced studies at baseline resulted in an effect of the intervention on BMI reduction ${ }^{(8)}$. The imbalance in BMI is a frequent methodological problem due to the cluster design $^{(9)}$ and small sample size across groups at baseline.

Most of the school interventions have been effective in changing behaviours associated with obesity ${ }^{(10)}$, and the lack of effect on BMI or other measures of body fat is possibly due to the small sample size combined with BMI heterogeneity, that is, students with obesity require more in-depth interventions at the family level. Therefore, the purpose of the present study

Abbreviations: \%body fat, percentage body fat; 24HR, 24-h food recall; CHA, community health agents; FHS, Family Health Strategy.

* Corresponding author: Michele R. Sgambato, email michelesgambato@hotmail.com 
was to evaluate the effectiveness of a combined school- and home-based obesity prevention programme, delivered by teachers and community health professionals, respectively, in a large sample of adolescents.

The Brazilian Family Health Strategy (FHS) programme has had a great impact in treating acute infectious diseases and undernutrition, but has not been used to address obesity at the family level. Families are visited by community health agents (CHA), whose activities are performed through household visits $^{(11)}$ supervised by a general practitioner, a generalist nurse and other health professionals.

\section{Method \\ Population and study design}

The present study was carried out in the Municipality of Duque de Caxias, state of Rio de Janeiro, Brazil (890 997 estimated inhabitants in 2017), a metropolitan area in Rio de Janeiro. It is one of the poorest municipalities in the state of Rio de Janeiro ${ }^{(12)}$ with most students at public schools having a low socioeconomic status. All students from fifth- and sixth-grade classes in the selected schools were eligible to participate, except disabled and pregnant adolescents.

The present study was labelled 'PAAPPAS' in Portuguese, which translates to 'Parents, students, community health agents and teachers for healthy eating'. The intervention aimed to improve diet quality, enhance regular physical activity and reduce sedentary behaviours by combining primary prevention of obesity at schools and secondary prevention of obesity at home among adolescents with obesity. The outcomes were change in BMI and change in percentage body fat (\%body fat).

PAAPPAS is a pragmatic trial where all intervention activities are implemented by the agents: teachers at school, and CHA from the FHS at the households ${ }^{(13)}$. The FHS is currently the main type of primary health care offered in Brazil. Each FHS nucleus covers a geographical area of reference encompassing a population of up to 4000 inhabitants $^{(14)}$.

In Duque de Caxias, twenty-seven out of the forty-two municipal public schools were in areas with FHS coverage. These schools were firstly stratified by size as small, medium and large, based on the number of fifth- and sixth-grade classes. Six schools in each stratum were randomly selected, resulting in eighteen schools to reach the calculated sample size, which were allocated randomly to the control or intervention group (nine schools in each group). Randomisation was conducted by research assistants unrelated to the present study using opaque envelopes.

The sample size calculation of 2500 students was based on a change of $1.1 \mathrm{BMI}$ units in the experimental group compared with the control group for the secondary intervention based on a previous study ${ }^{(15)}$, with a standard deviation (SD) of $3.0 \mathrm{~kg} / \mathrm{m}^{2}, 80 \%$ power and a $5 \%$ significance level. School classes from each one of the shifts (morning, afternoon and late afternoon) were the cluster unit with an intracluster correlation of $0.02^{(16)}$.

The trial was registered at ClinicalTrials.gov (NCT02711488).

\section{Interventions}

Six interventions of $50 \mathrm{~min}$ were planned to encourage students to adopt heathy eating and focus on physical activity. The content of the interventions was previously discussed with teachers of the eligible schools and adjusted according to the school programme.

Details of the study design and interventions were previously published $^{(16)}$. In short, interventions at schools were based on educational games, group debates and culinary classes with focus on: (1) reducing the intake of cookies and sugar-sweetened beverages; (2) assembling colourful and tasty salads using vegetables and fruits through culinary classes; (3) encouraging water consumption; (4) increasing physical activity and reducing sedentary behaviour; (5) serving a healthy meal; and (6) reducing the dependence on processed food.

Teachers from the intervention schools were trained to deliver the activities, and every month, from March to June and from August to September, they received material for a session of in-class activities. A culinary class was the first intervention, which was delivered by research assistants.

Intervention adhesion was verified by changes in food consumption and in physical activity level. To measure adherence, teachers were asked to report the activities they had conducted and the student's acceptance of each activity.

CHA led activities that stimulated lifestyle changes at the family level. The goals were the same as those of the school intervention with emphasis on reducing soda and sugar-sweetened beverages, cookies, sweets and processed food, and increasing fresh food intake. Seventy CHA belonging to the area of the intervention schools were trained 2 months before starting the school intervention. Two meetings, making a total of $16 \mathrm{~h}$ of training, were conducted for groups of a maximum of $20 \mathrm{CHA}$. Two instructors in each group helped the trainees through active learning strategies to develop a booklet used as a guide for household visits. The content and strategies to promote change in family diet and physical activity were elaborated after discussions and reflections of the eating habits of $\mathrm{CHA}$, their relatives and the observed habits of the community. The booklet is available at http://www.nebin.com.br/downloads/cartilha.pdf. Families were also informed on places available in the neighbourhood to increase physical activity as well as on strategies to reduce sedentary habits. Five interventions of approximately 20 min per month occurred from April to October.

\section{Data collection}

Baseline data were collected at schools from February to March and from November to December 2016 for postintervention data. Trained field researchers supervised a self-reported structured questionnaire using a personal digital assistant and measured weight and height using standardised procedures ${ }^{(17)}$. Height was measured using a portable stadiometer (AlturaExata), and weight and \%body fat were estimated using a tetrapolar bioelectrical impedance scale (Tanita BC-558). Weight status based on BMI was classified according to the WHO criteria ${ }^{(18)}$. Obesity and being overweight were defined, respectively, 
as overweight: $>+1 \mathrm{sD}$ (equivalent to BMI $25 \mathrm{~kg} / \mathrm{m}^{2}$ at 19 years); obesity: > +2 sD (equivalent to BMI $30 \mathrm{~kg} / \mathrm{m}^{2}$ at 19 years)

\section{Dietary consumption}

Food consumption was assessed with a short qualitative FFQ with twenty-three items, based on an FFQ validated for adolescents of Rio de Janeiro ${ }^{(19)}$ with seven categories of consumption: (1) less than once per month or never, (2) 1-3 times per month, (3) once per week, (4) 2-4 times per week, (5) 5-6 times per week, (6) once per $\mathrm{d}$ and ( 7 ) $\geq 2$ times per $\mathrm{d}$. The observed food frequencies were transformed into daily frequencies, and to estimate intake in grams, standard serving sizes used in the original validated $\mathrm{FFQ}^{(19)}$ were included into the database. A score to evaluate changes in food intake relating to the intervention was estimated by averaging the differences in food consumption frequency as follows: (milk + beans + water + fruits + vegetables $)-$ (cookies + sodas + processed meat + sugarsweetened fruit-based drinks). Milk and beans were considered markers of home-made or school lunch meals. Therefore, a more positive score indicates healthier items compared with less healthy items.

In a random subsample of $30 \%$ of participants, one $24-\mathrm{h}$ food recall (24HR) was collected at baseline and one at the end of the study. A Brazilian dietary database of a nationwide survey carried out with adolescents was used for data entrance ${ }^{(20)}$. Out of 983, sixteen $24 \mathrm{HR}$ records were excluded because these presented implausible values of energy consumption $(<500$ or $>5000$ ).

Physical activity practised during the $7 \mathrm{~d}$ prior to the study was evaluated based on time ( $\mathrm{min}$ ) to commute to school and exercising at school, and out of school using a validated questionnaire of the Brazilian National School-Based Health Survey $(\text { PeNSE) })^{(21)}$.

\section{Ethical and data protection}

The study design and intervention strategies were discussed and approved by the health and education municipal authorities. The trial protocol has been previously reported ${ }^{(16)}$ in accordance with the Consolidated Standards of Reporting Trials Statement ${ }^{(22)}$. The study protocol was approved by the Ethical Committee of the Social Medicine Institute (State University of Rio de Janeiro, Brazil). Only students with a written consent signed by their parents were measured, but all participated in class interventions. The protocol registration was CAAE 10471313.2.0000.5260. Further details on recruitment, sample size estimation, data collection, PAAPPAS interventions at school and statistical analysis are found in Sgambato et al. ${ }^{(16)}$.

\section{Statistical analysis}

Changes of BMI and \%body fat were analysed with mixed models for repeated continuous measures through the PROC MIXED procedure in Statistical Analysis System, version 9.3 (SAS Institute Inc.). The model used all information available (intention-to-treat analysis) and considered the cluster effect of classes $^{(23)}$. Main analyses were stratified by sex. Variation in the daily frequency of food consumption and physical activity
Table 1. Age, body weight, height, BMI, percentage body fat (\%body fat), percentage of overweight and obesity and race in the control and intervention groups at baseline

(Mean values and standard deviations; percentages)

\begin{tabular}{|c|c|c|c|c|}
\hline \multirow[b]{2}{*}{ Variable } & \multicolumn{2}{|c|}{$\begin{array}{l}\text { Control group } \\
\quad(n 1157)\end{array}$} & \multicolumn{2}{|c|}{$\begin{array}{l}\text { Intervention group } \\
\quad(n 1290)\end{array}$} \\
\hline & Mean & SD & Mean & $\mathrm{SD}$ \\
\hline Age (years) & 11.5 & 1.46 & 11.5 & 1.43 \\
\hline Body weight $(\mathrm{kg})$ & 43.9 & $12 \cdot 48$ & $44 \cdot 1$ & $12 \cdot 46$ \\
\hline Stature $(\mathrm{m})$ & 1.50 & 0.10 & 1.50 & $0 \cdot 10$ \\
\hline BMI (kg/m²) & $19 \cdot 1$ & 4.04 & $19 \cdot 2$ & 4.03 \\
\hline$\%$ Body fat & $22 \cdot 9$ & $7 \cdot 20$ & $23 \cdot 0$ & $7 \cdot 02$ \\
\hline \multicolumn{5}{|l|}{$\operatorname{Sex}(\%)$} \\
\hline Male & \multicolumn{2}{|c|}{$52 \cdot 1$} & \multicolumn{2}{|c|}{51.9} \\
\hline Female & \multicolumn{2}{|c|}{47.9} & \multicolumn{2}{|c|}{$48 \cdot 1$} \\
\hline \multicolumn{5}{|c|}{ Nutritional status (\%) } \\
\hline Overweight & \multirow{2}{*}{\multicolumn{2}{|c|}{$\begin{array}{l}18.1 \\
12.9\end{array}$}} & \multicolumn{2}{|c|}{$18 \cdot 6$} \\
\hline Obesity & & & \multicolumn{2}{|c|}{$13 \cdot 8$} \\
\hline \multicolumn{3}{|l|}{ Race (\%) } & & \\
\hline White & \multicolumn{2}{|c|}{$\begin{array}{l}27 \cdot 6 \\
23.5\end{array}$} & \multicolumn{2}{|c|}{$23 \cdot 1$} \\
\hline Black & & & & \\
\hline Mixed race & \multicolumn{2}{|c|}{48.9} & \multicolumn{2}{|c|}{52.5} \\
\hline
\end{tabular}

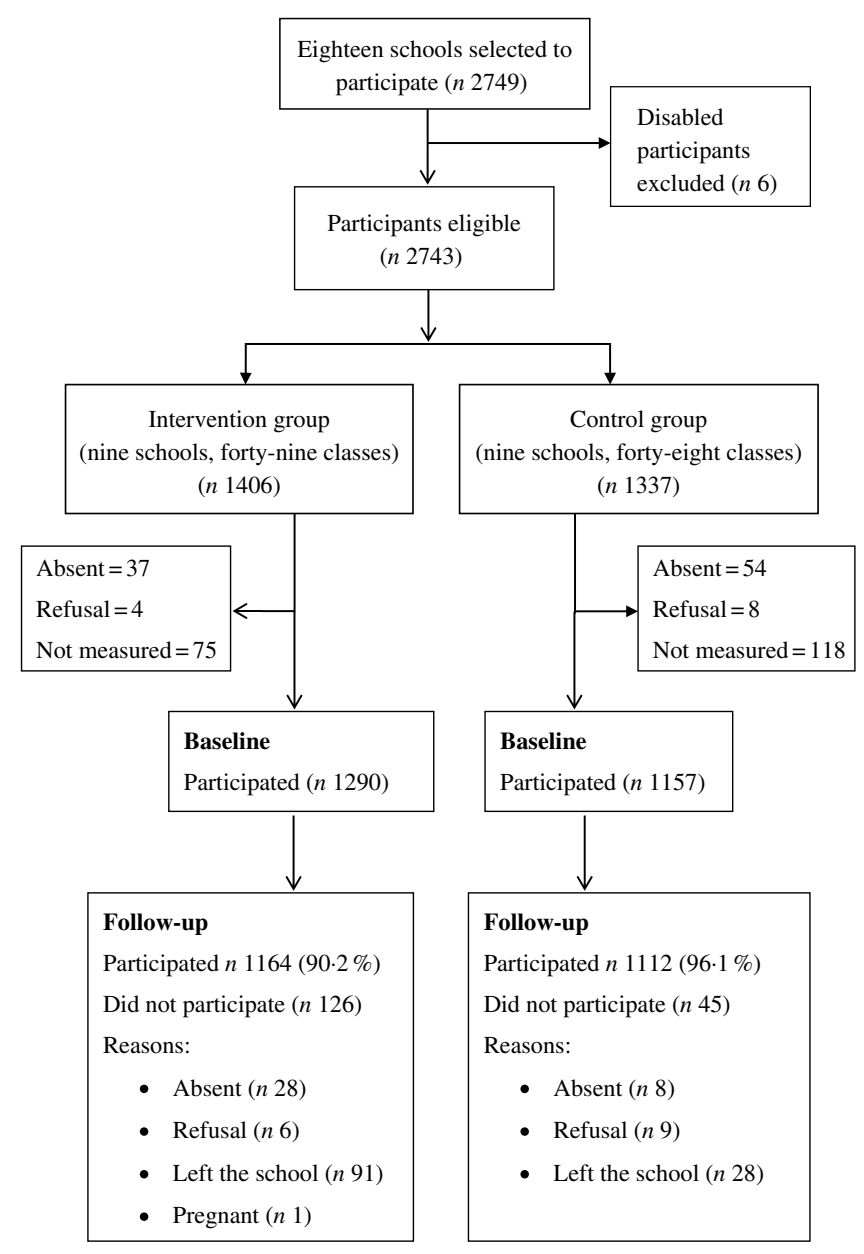

Fig. 1. Progress of individuals during study phases.

was also analysed as continuous variables using the PROC MIXED procedure. Random intercept and slopes were tested for the adequacy of the model. Data of specific food groups 
Table 2. Estimated mean* BMl and percentage body fat (\%body fat) and difference $(\Delta)$ by group from baseline to the end of school year (follow-up) (Mean values and differences)

\begin{tabular}{|c|c|c|c|c|c|c|c|}
\hline \multirow[b]{3}{*}{ Variable } & \multicolumn{3}{|c|}{ Control group } & \multicolumn{3}{|c|}{ Intervention group } & \multirow[b]{3}{*}{$P \dagger$} \\
\hline & $\begin{array}{l}\text { Baseline } \\
(n \text { 1157) }\end{array}$ & $\begin{array}{c}\text { Follow-up } \\
(n 1112)\end{array}$ & \multirow[b]{2}{*}{$\Delta$} & $\begin{array}{l}\text { Baseline } \\
(n \text { 1290) }\end{array}$ & $\begin{array}{l}\text { Follow-up } \\
(n 1164)\end{array}$ & \multirow[b]{2}{*}{$\Delta$} & \\
\hline & Mean & Mean & & Mean & Mean & & \\
\hline $\mathrm{BMI}\left(\mathrm{kg} / \mathrm{m}^{2}\right)$ & $19 \cdot 2$ & $19 \cdot 4$ & 0.2 & $19 \cdot 4$ & $19 \cdot 7$ & 0.3 & 0.05 \\
\hline $\begin{array}{l}\text { \%Body fat } \\
\text { Males }\end{array}$ & $23 \cdot 0$ & $22 \cdot 6$ & -0.4 & $23 \cdot 1$ & $23 \cdot 0$ & -0.1 & 0.01 \\
\hline BMI $\left(\mathrm{kg} / \mathrm{m}^{2}\right)$ & $19 \cdot 0$ & $19 \cdot 2$ & 0.2 & $19 \cdot 1$ & $19 \cdot 3$ & 0.2 & 0.32 \\
\hline $\begin{array}{l}\text { \%Body fat } \\
\text { Females }\end{array}$ & $20 \cdot 0$ & $19 \cdot 4$ & -0.6 & $20 \cdot 1$ & $19 \cdot 7$ & -0.4 & 0.03 \\
\hline BMI $\left(\mathrm{kg} / \mathrm{m}^{2}\right)$ & $19 \cdot 5$ & $19 \cdot 8$ & 0.3 & 19.7 & $20 \cdot 1$ & 0.4 & 0.11 \\
\hline \%Body fat & $26 \cdot 2$ & $26 \cdot 3$ & 0.1 & $26 \cdot 3$ & $26 \cdot 6$ & 0.3 & 0.13 \\
\hline
\end{tabular}

* Estimated based on PROC MIXED in SAS, adjusted for age.

$\dagger$ Interaction group $\times$ time, measuring change over time to compare groups.

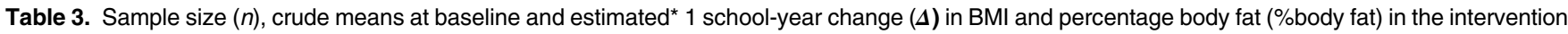
compared with the control group

(Mean values and standard deviations)

\begin{tabular}{|c|c|c|c|c|c|c|c|c|c|c|c|c|c|c|c|}
\hline \multirow[b]{2}{*}{ Variable } & \multicolumn{3}{|c|}{ Control } & \multicolumn{6}{|c|}{ Intervention adherence $†$} & \multicolumn{6}{|c|}{ Intervention secondarył } \\
\hline & $n$ & Mean & SD & $n$ & Mean & SD & $\Delta$ & SD & $P$ & $n$ & Mean & SD & $\Delta$ & SD & $P$ \\
\hline $\mathrm{BMI}\left(\mathrm{kg} / \mathrm{m}^{2}\right)$ & 1157 & $19 \cdot 1$ & 4.04 & 538 & $19 \cdot 1$ & 3.97 & 0.12 & 0.07 & 0.09 & 85 & $23 \cdot 7$ & $3 \cdot 33$ & 0.12 & 0.15 & 0.41 \\
\hline \%Body fat & 1167 & $22 \cdot 9$ & $7 \cdot 20$ & 542 & $22 \cdot 8$ & $7 \cdot 22$ & 0.38 & 0.17 & 0.02 & 85 & 29.0 & 6.69 & 0.89 & 0.36 & 0.01 \\
\hline
\end{tabular}

* Estimated based on PROC MIXED in SAS, adjusted for age and sex

$\dagger$ Adherence $=$ subgroup with more than three interventions.

‡ Secondary = subgroup with school and household interventions.

associated with the intervention measured by one $24 \mathrm{HR}$ at baseline and one at follow-up had high percentages of zero intake. These analyses for all groups except for beans $(<10 \%$ for lack of consumption) in a given day were made using marginal generalised linear models (PROC GENMOD procedure) with gamma distribution. Variation was treated as mean change in grams.

Beyond the main intention-to-treat analysis, subgroup analyses by adherence per protocol were also conducted for those students participating in more than three school activities. Also, overweight and obese students who received the secondary intervention at home were compared with the control group.

\section{Ethical approval and consent to participate}

The study was approved by the Ethics Committee of the Institute of Social Medicine (Comitê de ética do Instituto de Medicina Social - CAAE: 10471313.2.0000.5260). Written informed consent was obtained from a parent of every participant.

\section{Consent for publication}

The manuscript does not contain any personal data in any form (including details, images and videos of individuals).

\section{Availability of data and material}

Datasets generated by the present study are not publicly available, but can be sourced from the corresponding author on reasonable request.

\section{Results}

Intervention and control groups were well balanced in total numbers (1406 v. 1337) with small losses to follow-up, which were slightly higher in the intervention group (9.8 v. 3.9\%; Fig. 1). Means of weight, BMI and \%body fat, and prevalence of obesity were balanced at baseline (Table 1). BMI changed in the two groups with a slightly greater increase in the intervention $\left(0.3 \mathrm{~kg} / \mathrm{m}^{2}\right)$ compared with the control group $\left(0.2 \mathrm{~kg} / \mathrm{m}^{2}\right.$; $P=0.05)$. Although both groups showed small yet significant reductions in \%body fat, the decrease was less in the intervention group compared with the control group. This difference in $\%$ body fat in the intervention group was significant in boys only (Table 2).

In the intervention group, $41.7 \%$ students received four or more interventions and $21 \%$ received all six interventions. About $20 \%$ of students ( $n$ 85) with obesity received two or more visits at home by the CHA. Subgroup analyses indicated that those who participated in the home-based intervention and those who participated in the group with high adherence had results that were quite similar to the overall results, with a higher increase in \%body fat. Change in \%body fat was clinically relevant in the secondary intervention group compared with the control group ( $\Delta=0.89 \% ; P=0.01$ ) (Table 3 ).

Estimated changes in the daily frequency of intake of food groups were small. There were no significant changes in daily food frequencies of each food group, between the intervention and control groups, nor any significant results when restricted to 
Table 4. Daily frequency of intake and duration of physical activity per week and estimated variation $(\Delta) \dagger$ during 1 school-year according to intervention and adherence to protocol

(Mean values, and variations and standard deviations)

\begin{tabular}{|c|c|c|c|c|c|c|c|c|c|c|}
\hline \multirow[b]{3}{*}{ Food item } & \multirow{2}{*}{\multicolumn{2}{|c|}{$\begin{array}{c}\text { Control } \\
\text { Mean } \\
\end{array}$}} & \multirow{2}{*}{\multicolumn{2}{|c|}{$\begin{array}{c}\text { Intervention all } \\
\text { Mean }\end{array}$}} & \multirow[b]{3}{*}{$\Delta$} & \multirow[b]{3}{*}{ SD } & \multirow{2}{*}{\multicolumn{2}{|c|}{$\begin{array}{c}\text { Intervention } \\
\text { adherencef } \\
\text { Mean }\end{array}$}} & \multirow[b]{3}{*}{$\Delta$} & \multirow[b]{3}{*}{ SD } \\
\hline & & & & & & & & & & \\
\hline & $\begin{array}{l}\text { Baseline } \\
(n \text { 1203) }\end{array}$ & $\begin{array}{l}\text { Follow-up } \\
(n \text { 1109) }\end{array}$ & $\begin{array}{l}\text { Baseline } \\
(n \text { 1322) }\end{array}$ & $\begin{array}{l}\text { Follow-up } \\
(n 1161)\end{array}$ & & & $\begin{array}{l}\text { Baseline } \\
(n 552)\end{array}$ & $\begin{array}{l}\text { Follow-up } \\
(n \text { 485) }\end{array}$ & & \\
\hline Milk (a glass; 200 ml) & 0.48 & 0.50 & 0.47 & 0.51 & -0.009 & 0.53 & 0.45 & 0.56 & 0.021 & 0.02 \\
\hline Beans (a ladle; $100 \mathrm{~g}$ ) & 0.92 & 0.98 & 0.91 & 0.98 & -0.025 & 0.02 & 0.91 & 0.96 & -0.003 & 0.02 \\
\hline Water (a glass; $200 \mathrm{ml}$ ) & 3.39 & 3.36 & 3.45 & 3.27 & -0.018 & 0.02 & 3.42 & 3.22 & -0.025 & 0.03 \\
\hline Fruits (one unit; $100 \mathrm{~g}$ ) & 0.84 & 0.87 & 0.82 & 0.84 & 0.016 & 0.02 & 0.80 & 0.84 & 0.033 & 0.02 \\
\hline $\begin{array}{l}\text { Vegetables (three } \\
\text { tablespoons; } 75 \mathrm{~g} \text { ) }\end{array}$ & 0.49 & 0.51 & 0.49 & 0.51 & 0.006 & 0.01 & 0.48 & 0.51 & 0.000 & 0.02 \\
\hline Cookies $(1 / 2$ package; $85 \mathrm{~g})$ & 0.59 & 0.59 & 0.57 & 0.62 & 0.007 & 0.01 & 0.57 & 0.60 & -0.013 & 0.02 \\
\hline Sodas (a glass; $200 \mathrm{ml}$ ) & 0.70 & 0.67 & 0.68 & 0.69 & -0.025 & 0.02 & 0.65 & 0.66 & -0.036 & 0.02 \\
\hline $\begin{array}{l}\text { Processed meat } \\
\text { (a slice; } 15 \mathrm{~g} \text { ) }\end{array}$ & 0.64 & 0.63 & 0.62 & 0.66 & -0.011 & 0.01 & 0.61 & 0.64 & -0.013 & 0.02 \\
\hline $\begin{array}{l}\text { Fruit-based drinks } \\
\text { (a glass; } 200 \mathrm{ml} \text { ) }\end{array}$ & 0.84 & 0.78 & 0.80 & 0.82 & 0.023 & 0.02 & 0.78 & 0.81 & $0.042^{\star *}$ & 0.02 \\
\hline $\begin{array}{l}\text { Physical activity } \\
\text { (min per week) }\end{array}$ & 258 & 266 & 232 & 284 & $12 \cdot 50^{*}$ & $6 \cdot 17$ & 254 & 286 & $20 \cdot 14^{*}$ & 8.04 \\
\hline
\end{tabular}

${ }^{*} P<0.05 ;{ }^{* *} P=0.05$.

$\dagger$ Estimated based on PROC MIXED in SAS, adjusted for age and sex.

$\ddagger$ Adherence $=$ subgroup with more than three interventions.

Table 5. Change in daily frequency of intake according to intervention and sex

(Mean values and standard deviations)

\begin{tabular}{|c|c|c|c|c|c|c|c|c|}
\hline \multirow[b]{3}{*}{ Item } & \multicolumn{4}{|c|}{ Males } & \multicolumn{4}{|c|}{ Females } \\
\hline & \multicolumn{2}{|c|}{ Control (n 528) } & \multicolumn{2}{|c|}{ Intervention ( $n$ 566) } & \multicolumn{2}{|c|}{ Control (n 475) } & \multicolumn{2}{|c|}{ Intervention ( $n$ 524) } \\
\hline & Mean & SD & Mean & SD & Mean & SD & Mean & SD \\
\hline Milk (a glass) & $0 \cdot 10$ & 2.63 & 0.00 & $2 \cdot 82$ & -0.15 & $2 \cdot 86$ & 0.01 & $2 \cdot 85$ \\
\hline Beans (a ladle) & 0.12 & $2 \cdot 83$ & 0.07 & 2.74 & 0.06 & $2 \cdot 68$ & 0.29 & 2.95 \\
\hline Water (a glass) & -0.04 & $1 \cdot 19$ & -0.14 & $1 \cdot 11$ & $-0 \cdot 10$ & 0.87 & -0.13 & 1.05 \\
\hline Fruits (one unit) & 0.14 & 2.52 & 0.06 & 2.72 & -0.10 & $2 \cdot 71$ & 0.14 & $2 \cdot 75$ \\
\hline Vegetables & 0.03 & $2 \cdot 55$ & 0.02 & $2 \cdot 70$ & 0.02 & $2 \cdot 76$ & $0 \cdot 16$ & $2 \cdot 75$ \\
\hline Cookies (1/2 package) & 0.05 & 2.68 & 0.23 & 2.62 & 0.00 & 2.79 & 0.15 & 2.78 \\
\hline Sodas (a glass) & -0.14 & 2.64 & -0.03 & $2 \cdot 70$ & -0.04 & $2 \cdot 67$ & -0.00 & 2.78 \\
\hline Processed meat (a slice) & -0.02 & $2 \cdot 76$ & 0.26 & 2.79 & -0.08 & $2 \cdot 56$ & 0.01 & $2 \cdot 83$ \\
\hline Fruit-based drinks (a glass) & -0.04 & $2 \cdot 78$ & $0 \cdot 10$ & 2.69 & -0.26 & $2 \cdot 79$ & -0.02 & 2.98 \\
\hline Score change ${ }^{*}$ & 0.51 & 6.64 & -0.55 & 7.08 & 0.11 & $7 \cdot 19$ & 0.29 & 7.89 \\
\hline$P_{\text {score change }}$ & 0.13 & & & & 0.04 & & & \\
\hline
\end{tabular}

* Score $=$ (sum of healthy items) - (sum of unhealthy items).

the adherence subgroup. Physical activity significantly increased ( $\Delta=12.50$ min per week; $P=0.01$ ) in the intervention group compared with the control group (Table 4). Yet, summing up the daily intake of the nine food groups showed a significant difference in the score of girls in the intervention group, compared with the control group. A more positive score means healthier changes (Table 5).

The analyses of $24 \mathrm{HR}$ based on a $30 \%$ subsample of students indicated a significant decrease in fruit juice intake in the intervention group compared with the control group $(\Delta=-0.42$; SD 0.18). The total energy intake at baseline was 2094 (SD 780) kcal (8761 (sD 3264) kJ) for the control group and 2331 (sD 845$) \mathrm{kcal}$ (9753 (sD 3535) kJ) for the intervention group; and at follow-up, these values were 2322 (sD 888) kcal (9715 (sD 3715) kJ) and 2293 (sD 858) kcal (9594 (sD 3590) kJ), respectively, with no difference between the groups.

\section{Discussion}

This pragmatic school trial combining teacher-delivered primary prevention of obesity at school and secondary prevention at household led by CHA showed a small, statistically significant increase in physical activity and a small change in the overall intake of healthy food without the expected impact in BMI or \%body fat. These findings are consistent with other studies conducted in adolescents suggesting no positive effect of behaviour intervention on BMI change ${ }^{(24-26)}$.

The design of the study - closer to a pragmatic trial design ${ }^{(13)}$, with large sample size, balanced baseline BMI values, the latter usually a major problem with cluster design - was expected to define the role of a comprehensive behavioural intervention on the prevention of excessive weight gain. By incorporating actions at the household level and including over 2000 
participants, major pitfalls were overcome in the present study; in spite of this, no effect was observed in the markers of obesity, with \%body fat being greater in the intervention group compared with the control group by study end. These results were quite similar to a small explanatory study without family participation, with interventions delivered by research assistants carried out in the same city of the present study ${ }^{(27)}$, where the participation of students in the intervention was about $100 \%$. In this explanatory trial using the same class approach, a decrease in the consumption of sugar, sugar-sweetened beverages and processed snacks was found, also without a positive change in $\mathrm{BMI}^{(27)}$. In the present study, adherence was much lower, and only $41.7 \%$ participated in more than three class interventions. Also, changes in each marker of food intake relating to the intervention were minimal, but change in healthy food intake was positive as well as change in physical activity. A sub-analysis of those students with greater adherence and of those with secondary intervention revealed the same association of the overall analysis, indicating that adherence to the intervention did not bias the results.

Behavioural interventions relating to food intake in the present study and in many of the school trials are mainly related to the quality of foods, such as increased intake of fruits and salads and reduction of ultra-processed foods ${ }^{(28)}$. These interventions focused only on improvement of the quality of food in the environment (school and at home). There were no interventions focused, for example, on decreasing the amount of food. Indeed, a review of the impact of fruit and vegetable intake on adiposity among children could not find a protection effect $^{(29)}$. The intake of fruits and vegetables in isolation does not appear to shift the intake of high-energy foods as shown in an analysis of household food diversity, with no replacement of unhealthy food groups by healthy foods ${ }^{(30)}$.

In the present study, the intervention worsened the problem of body fat, instead of improving it. This hypothesis is not out of possibility, since a study carried out with Brazilian adolescents with the purpose of evaluating the effectiveness of a brief intervention and preventive guidance on the use of alcohol and marijuana found that a single intervention session increased alcohol experimentation $^{(31)}$. In our case, we offered the students new possibilities of combining vegetables and fruits and exhorted them to increase fruit intake, which could possibly explain the changes in behaviour and fatness indicators. Fruit juice intake was not stimulated, but as observed in a trial designed to reduce sodas, fruit juices with a high sugar content replaced sodas ${ }^{(15)}$. Thus, the inclusion of healthy foods in the diet of adolescents does not appear to reduce the intake of other less healthy products. However, longer-lasting behaviour interventions might be beneficial, even if they do not affect weight trajectories in 1 year.

It cannot be excluded that reported behaviour changes observed in dietary interventions are related to the social desirability bias. Sex is known to influence social desirability ${ }^{(32)}$; however, reported changes were expected to be more significant among girls in this case.

With approximately $32 \%$ of adolescents who were overweight or obese in the present study, and an even higher prevalence being observed in the private schools in Brazil ${ }^{(33)}$, a reduction in total energy intake is a needed message but challenging to accomplish. Guidelines for children and adolescents recommend caution on reduction in food intake since restrictive behaviours are related to eating disorders ${ }^{(34)}$. New policies relating to portion size strategies may be an option. Changes in food supply may address important environment clues that may impact long-term behaviour change ${ }^{(35)}$.

Possible limitations of the study were: (1) low adherence to the protocol, which does not seem to explain the increase in adiposity; (2) only about $20 \%$ of the overweight students were visited for secondary intervention by the CHA because some residences were hard to be reached and some families were not registered in the FHS. However, results observed in this subsample are not only in the same direction of the overall results, but also statistically significant. (3) Power of the study, even with $>2000$ participants, was inadequate since classes, instead of schools, were assumed as the cluster. This limitation would bias the results towards the null hypothesis, but the main result was a small but significant increase in adiposity measured by \%body fat.

One strength of the intervention is the chosen age group because puberty was expected to facilitate a reduction in weight gain due to adolescence spurt. Also, changes in weight gain around the time of puberty have an important impact on a reduction of the risk of adulthood diabetes ${ }^{(36)}$. The low participation rate of teachers and CHA even after extensive training is to be noted, indicating the difficulty to incorporate obesity prevention action as a routine.

The lack of effectiveness relating to the prevention of obesity in most behaviour studies is due to the complexity of food consumption behaviour. There are important factors that influence adolescents' eating habits ${ }^{(37)}$, such as family environment (which we tried to include), friends and the media. In the present study, the intervention strategy based on physical activity was successful although with no impact on the reduction of weight gain, and change was small as expected. Strategies of portion size reduction may be an option to be tested in further studies.

In conclusion, this large trial including physical activity and eating behaviour intervention with the participation of CHA, family, and teachers did not indicate a reduction in obesity, also suggesting a possibility of an opposite result.

\section{Acknowledgements}

We are indebted to all students and teachers who participated in the study, and we thank the Health Secretary and Education Secretary of the municipality of Duque de Caxias for their partnership in this project.

The study was supported by Conselho Nacional de Desenvolvimento Científico e Tecnológico and Fundação de Amparo à Pesquisa do Estado do Rio de Janeiro.

R. S. is the principal investigator. R. S., R. A. P., E. M. Y., and D.B. C. conceived and designed the study. M. R. S. supervised data collection and wrote the paper. R. S., M. R. S., B. S. N. S., R. R. M. R., and A. L. V. R. contributed to data analysis. All authors contributed to revising the manuscript, and all read and approved the final manuscript.

None of the authors has conflicts of interest. 


\section{References}

1. World Health Organization (2017) Obesity and Overweight. Geneva: WHO. http://www.who.int/mediacentre/factsheets/ fs311/en/ (accessed January 2018).

2. Bloch KV, Klein CH, Szklo M, et al. (2016) ERICA: prevalence of hypertension and obesity in Brazilian adolescents. Rev Saúde Pública 50, Suppl. 1, 9s.

3. Souza AM, Pereira RA, Yokoo EM, et al. (2013). Most consumed foods in Brazil: Nacional Dietary Survey 2008-2009. Rev Saúde Pública 47, Suppl. 1, 190S-199S

4. Wang Y, Cai L, Wu Y, et al. (2015) What childhood obesity prevention programmes work? A systematic review and meta-analysis. Obes Rev 16, 547-565.

5. Rahman AA, Jomaa L, Kahale LA, et al. (2018) Effectiveness of behavioral interventions to reduce the intake of sugarsweetened beverages in children and adolescents: a systematic review and meta-analysis. Nutr Rev 76, 88-107.

6. Sobol-Goldberg S, Rabinowitz J \& Gross R (2013) School-based obesity prevention programs: a meta-analysis of randomized controlled trials. Obesity (Silver Spring) 21, 2422-2428.

7. Okely AD \& Hammersley ML (2018) School-home partnerships: the missing piece in obesity prevention? Lancet Child Adolesc Health 2, 5-6.

8. Kong K, Liu J \& Tao Y (2016) Limitations of studies on schoolbased nutrition education interventions for obesity in China: a systematic review and meta-analysis. Asia Pac J Clin Nutr 25 589-601.

9. Sichieri R \& Cunha DB (2014) Unbalanced baseline in schoolbased interventions to prevent obesity: adjustment can lead to bias - a systematic review. Obesity Facts 7, 221-232.

10. Verstraeten R, Roberfroid D, Lachat C, et al. (2012) Effectiveness of preventive school-based obesity interventions in low- and middle-income countries: a systematic review. Am J Clin Nutr 96, 415-438.

11. Rodrigues LBB, Silva PCS, Peruhype RC, et al. (2014) A Atenção Primária à Saúde na coordenação das redes de atenção: uma revisão integrativa (Primary Health Care in the coordination of care networks: an integrative review). Ciênc Saúde Colet 19, 343-352.

12. Instituto Brasileiro de Geografia e Estatística (2010) População (Population). Rio de Janeiro: Instituto Brasileiro de Geografia e Estatística. https://cidades.ibge.gov.br/brasil/ri/duque-de-ca xias/panorama (accessed June 2018).

13. Loudon K, Treweek S, Sullivan F, et al. (2015) The PRECIS-2 tool: designing trials that are fit for purpose. BMJ 350, h2147.

14. BRASIL. Ministério da Saúde (2012) Política Nacional de Atenção Básica. Brasilia: Ministério da Saúde (Série E. Legislação em Saúde). http://dab.saude.gov.br/portaldab/biblioteca.php?cont eudo $=$ publicacoes/pnab (accessed November 2018).

15. Sichieri R, Trotte A, Souza RA, et al. (2009) School randomized trial on prevention of excessive weight gain by discouraging students from drinking sodas. Public Health Nutr 12, 197-202.

16. Sgambato MR, Cunha DB, Henriques VT, et al. (2016) PAAPPAS community trial protocol: a randomized study of obesity prevention for adolescents combining school with household intervention. BMC Public Health 16, 809.

17. Gordon CC, Chumlea WC \& Roche AF (1988) Stature, recumbent length, and weight. In Anthropometric Standardization Reference Manual, pp. 3-8 [CC Gordon, WC Chumlea and AF Roche, editors]. Champaign, IL: Human Kinetics Books.

18. de Onis M, Onyango AW, Borghi E, et al. (2007) Development of a WHO growth reference for school-aged children and adolescents. Bull World Health Organ 85, 660-667.
19. Araujo MC, Yokoo EM \& Pereira RA (2010) Validation and calibration of a semiquantitative food frequency questionnaire designed for adolescents. I Am Diet Assoc 110, $1170-1177$

20. Barufaldi LA, Abreu GA, Veiga GV, et al. (2016) Software to record 24-hour food recall: application in the Study of Cardiovascular Risks in Adolescents. Rev Bras Epidemiol 19, 464-468.

21. Tavares LF, Castro IRR, Cardoso LO, et al. (2014) Validade de indicadores de atividade física e comportamento sedentário da Pesquisa Nacional de Saúde do Escolar entre adolescentes do Rio de Janeiro, Brasil (Validity of physical activity indicators and sedentary behaviour of the National School Health Survey among adolescents from Rio de Janeiro, Brazil). Cad Saúde Pública 30, 1861-1874.

22. Boutron I, Altman DG, Moher D, et al. (2017) CONSORT statement for randomized trials of nonpharmacologic treatments: a 2017 update and a CONSORT extension for nonpharmacologic trial abstracts. Annals of internal medicine. Am Coll Physicians 167, 40.

23. Singer JD \& Willett JB (2003) Applied Longitudinal Data Analysis - Modeling Change and Event Occurrence. New York: Oxford University Press.

24. Klesges RC, Obarzanek E, Kumanyika S, et al. (2010) The Memphis Girls' health Enrichment Multi-site Studies (GEMS): an evaluation of the efficacy of a 2-year obesity prevention program in African American girls. Arch Pediatr Adolesc Med 164, 1007-1114

25. Rosenkranz RR, Behrens TK \& Dzewaltowski DA (2010) A group-randomized controlled trial for health promotion in Girl Scouts: healthier troops in a SNAP (Scouting Nutrition \& Activity Program). BMC Public Health 10, 81.

26. Ezendam NP, Brug J \& Oenema A (2012) Evaluation of the Web-based computer-tailored FATaintPHAT intervention to promote energy balance among adolescents: results from a school cluster randomized trial. Arch Pediatr Adolesc Med 166, 248-255.

27. Cunha DB, Souza BSN, Pereira RA, et al. (2013) Effectiveness of a randomized school-based intervention involving families and teachers to prevent excessive weight gain among adolescents in Brazil. PLOS ONE 8, e 57498.

28. Louzada MLC, Martins APB, Canella DS, et al. (2015) Ultraprocessed foods and the nutritional dietary profile in Brazil. Rev Saúde Pública 49, 38

29. Ledoux TA, Hingle MD \& Baranowski T (2011) Relationship of fruit and vegetable intake with adiposity: a systematic review. Obes Rev 12, e143-e150.

30. Bezerra IN \& Sichieri R (2011) Household food diversity and nutritional status among adults in Brazil. Int J Behav Nutr Phys Act Mar 27, 8-22.

31. De Micheli D, Fisberg M \& Formigoni MLOS (2004) Estudo da efetividade da intervenção breve para o uso de álcool e outras drogas em adolescentes atendidos num serviço de assistência primária à saúde (Study of the effectiveness of a brief intervention for the use of alcohol and other drugs in adolescents treated at an adolescent primary health care service). Rev Assoc Med Bras 50, 305-313.

32. Hebert JR, Ma Y, Clemow L, et al. (1997) Gender difference in social desirability and social approval bias in dietary self-report. Am J Epidemiol 146, 1046-1055.

33. Moreira N, Sichieri R, Reichenheim ME, et al. (2015) The associations of BMI trajectory and excessive weight gain with demographic and socio-economic factors: the Adolescent 
Nutritional Assessment Longitudinal Study cohort. Br J Nutr 114 2032-2038.

34. Neumark-Sztainer D, Wall M, Guo J, et al. (2006) Obesity, disordered eating, and eating disorders in a longitudinal study of adolescents: how do dieters fare 5 years later? J Am Diet Assoc 106, 559-568.

35. Mattes RD (2018) Evidence on the 'normalizing' effect of reducing food-portion sizes. Am J Clin Nutr 107, 501-503.
36. Bjerregaard LG, Jensen BW, Ängquist L, et al. (2018) Change in overweight from childhood to early adulthood and risk of type 2 diabetes. $N$ Engl J Med 378, 1302-1312.

37. Tarabashkina L, Quester P \& Crouch R (2016) Food advertising, children's food choices and obesity: interplay of cognitive defences and product evaluation: an experimental study. Int J Obes (Lond) 40, 581-586. 